\title{
Delay in Seeking Referral Treatment among Breast Cancer Patients at Ocean Road Cancer Institute and Muhimbili National Hospitals Dar Es Salaam, Tanzania
}

\author{
Angelina C. Mtowa* \\ Research and Developmet, Tanzania Community of Cancer Survivor, Dar es salaam, United Republic of Tanzania
}

\section{Objective}

To explore factors associated with delay in seeking referral for cancer treatment among breast cancer patients

\section{Introduction}

In Tanzania, cancer is recognized as a serious health care problem (ORCI, 2008) and is one of the major causes of mortality, morbidity, and disease burden. Tanzania with a population of 42.5 million people, it was estimated that 21,000 new cancer cases occur each year (Ferlay et al., 2008), out of this only $10 \%$ of these new cases manage to get proper care and treatment (MEWATA, 2008). Breast cancer is an issue of public health concern in Tanzania (MEWATA, 2008). It ranks third after cancer of the cervix and kaposis sarcoma and it accounts $9.3 \%$ of all cancers seen at Ocean Road Cancer Institute (ORCI). The Ocean Road Cancer Institute (ORCI) and Muhimbili National Hospital (MNH) are the health facilities which receive cancer patients from all over Tanzania. From the Newly diagnosed cancer, Less than $10 \%$ of patients are able to go for treatment at ORCI, and of this population $80 \%$ arrive when the cancer is too far advanced to treat effectively (Walker, 2007). Hence this paper focuses on factors which contributing to the delay of breast cancer patients to seek treatment at the tertiary hospitals after being diagnosed.

\section{Methods}

This was analytical cross-sectional study design involved either in-patient or out-patient services at the ORCI and MNH. The convenient sampling technique was used, Informed consent for participation in the study for breast cancer patients was sought verbally or written. Data were analyzed using STATA.

\section{Results}

This study recruited 142 study participants 24 from MNH and 118 from ORCI. Their mean age was 53 years and $62 \%$ were married, $21 \%$ employed. About $16 \%$ of the study participants were literate, $29 \%$ having completed at least a primary education. Then those who delayed in seeking treatment for more than three months were asked for the reasons for their delay for seeking health care after being diagonised with breast cancer. Among them, 34\% said cost of treatment, $15 \%$ said distance to ORCI/MNH, 37\% said they were receiving treatment at the traditional healers and $14 \%$ said misinformation about treatment offered at ORCI/MNH. About $69 \%$ and $46 \%$ of breast cancer patients with the age range of $50-69$ reported at the tertiary hospitals when the cancer is at stage I and II respectively. These findings implies that patient spend more time seeking treatment at the traditional healers and resulted into presentation at the tertiary hospitals when cancer is at advanced stage and hence difficult to cure.

\section{Conclusions}

This study provides very vital information which will assist the Ministry of Health and Social Welfare to design strategies that will enable breast cancer patients to present early for treatment after being diagnosed.
Main Reasons for Patient Delay Seeking Treatment at Ocean Road Cancer Institute and Muhimbili National Hospital

\begin{tabular}{|c|c|c|}
\hline $\begin{array}{c}\text { Main Reasons for Patient Delay Seeking Treatment at Ocean Road Cancer Institute and } \\
\text { Muhimbili National Hospital }\end{array}$ & frequency $\%$ \\
\hline Cost & 20 & 34 \\
\hline Distance & 9 & 15 \\
\hline Receiving treatment at the traditional healer & 22 & 37 \\
\hline Misinformation about treatment offered at ORCI and MNH & 8 & 14 \\
\hline Total & 59 & 100 \\
\hline
\end{tabular}

\section{Keywords}

Breast Cancer; Delay in seeking treatment; cancer stages

\section{Acknowledgments}

This work was supported by sponsorship provided by the collaboration between Muhimbili University of Health and Allied Sciences (MUHAS) and Center for Diseases Control (CDC).

\section{References}

Ferlay J, Shin R, Bray F, Forman D, Mathers D, Parkin D. (2008). GLOBOCAN, Cancer Incidence and Mortality Worldwide: IARC Cancer Base No. 10. Lyon, France: International Agency for Research on Cancer

MEWATA, (2008). Breast Cancer Screening Campaign Programme. Ocean Road Cancer Institute, (2008). Overview of cancer in Tanzania. Walker A. (2007). Perceptions of Family Cancer Caregivers in Tanzania: A Qualitative

\author{
*Angelina C. Mtowa \\ E-mail: amtowa2001@yahoo.com
}

